\title{
The Influence of Circadian Gene Per2 on Cell Damaged by Ultraviolet C
}

\author{
Yanyou Liu ${ }^{1,2}$, Yuhui Wang ${ }^{1}$, Zhou Jiang ${ }^{1}$, Jing Xiao' and Zhengrong Wang ${ }^{1,2, *}$ \\ ${ }^{1}$ Key Laboratory of Chronobiology, Ministry of Health (Sichuan University), West China School of Preclinical and Forensic Medicine, \\ ${ }^{2}$ State Key Laboratory of Biotherapy, Sichuan University, Chengdu, Sichuan 610041, PR China
}

\begin{abstract}
It has been shown that circadian genes not only play an important role on circadian rhythms, but also participate in other physiological and pathological activities, such as drug dependence, cancer development and radiation injury. The Per2, an indispensable component of the circadian clock, not only modulates circadian oscillations, but also regulates organic function. In the present study, we applied mPER2-upregulated NIH3T3 cells to reveal the relationship of mPer2 and the cells damaged by ultraviolet $\mathrm{C}$ (UVC). NIH3T3 cells at the peak of the expression of mPer2 induced by phorbol 12-myristate 13-acetate (PMA) demonstrated little damage by UVC evaluated by MTT assay, cell growth curves and cell colony-forming assay, compared with that at the nadir of the expression of mPer2. Overexpression of mPER2, accompanied p53 upregulated, also demonstrated protective effect on NIH3T3 cells damaged by UVC. These results suggest that $m P e r 2$ plays a protective effect on cells damaged by UVC, whose mechanism may be involved in upregulated $\mathrm{p} 53$.
\end{abstract}

Key Words: Circadian, mPer2, p53, ultraviolet C, DNA damage

\section{INTRODUCTION}

Circadian rhythms enable organisms to adapt to environmental changes such as light, temperature and social communication, and serve to synchronize multiple molecular, biochemical, physiological and behavioral processes (Panda et al., 2002; Delaunay and Laudet, 2002; Storch et al., 2002), which are daily oscillations regulated by an endogenous clock (Czeisler et al., 1999; Morse and Sassone-Corsi, 2002; Reppert and Weaver, 2002). The mechanisms of circadian rhythms are based on autoregulatory transcription and translation feedback loops of these circadian genes including Clock, Bmai1, Cry1, Cry2, Per1 and Per2, in which Per genes occupy a central position (Ebisawa et al., 2001; Fu et al., 2002; Reppert and Weaver, 2002). It has been shown that circadian genes not only play an important role on circadian rhythms, but also participate in other physiological and pathological activities, such as drug dependence (Andretic et al., 1999; Abarca et al., 2002; Liu et al., 2005), cancer development (Filipski et al., 2002), radiation injury (Haus, 2002), and DNA damage reaction (Fu et al., 2002).

There are photosensitive molecules receiving photons in ultraviolet (UV) radiation in cells, which lift electrons to a higher energy state. A chromophore may pass its excited energy to another molecule (Tyrrell, 1994). The main cellular chromophores for UV radiation are DNA and reactive oxygen-generating chromophores. Due to the aromatic ring structures of its bases, DNA absorbs shortwave length UV very efficiently and is the main chromophore for UVC, but absorbs also a significant amount of energy from UVB (de Gruijl et al., 2001; Ravanat et al, 2001). The most apparent types of UV radiation-induced DNA damage are cyclobutane-type pyrimidine dimers (CPDs) and (6-4)-photoproducts (6-4PPs), which cross-link adjacent DNA bases (Ravanat et al., 2001). These UV induced distortions in the DNA helix halt RNA polymerase (RNAP) elongation along DNA, thus inhibiting gene expression (Tornaletti and Hanawalt, 1999).

Transcriptional responses to different wavelengths and doses of UV radiation have been studied in different cell types of skin, including keratinocytes (Sesto et al., 2002; Takao et al., 2002; Dazard et al., 2003; He et al., 2004), melanocytes (Valery et al., 2001), and fibroblasts (Gentile et al., 2003; McKay et al., 2004), which have similar transcriptional targets that involve DNA damage repair, cell cycle arrest, and/or apoptotic machinery. UV doses causing either cell cycle arrest or apoptosis provoke transcriptionally highly divergent responses (Gentile et al., 2003). These are translated to responses of replicative arrest, damage repair, and apoptosis aimed at cel- www.biomolther.org

Open Access DOI: 10.4062/biomolther.2011.19.3.308

pISSN: 1976-9148 elSSN: 2005-4483

Copyright $\odot 2011$ The Korean Society of Applied Pharmacology
Received Jan 6, 2011 Revised May 1, 2011 Accepted May 2, 2011

\section{* Corresponding Author}

E-mail: wangzhengrong@126.com

Tel: +86-28-85501287, Fax: +86-28-85503204 
lular recovery from the damage.

p53 plays an important role in the context of ionizing radiation, other double strand break (DSB)-inducing agents and UV (Fei and El-Deiry, 2003; Meek, 2004; Leena and Marikki, 2005). Following UV damage, p53 levels and activity are subsequently increased and lead to transcriptional activation of its target genes responsible for cell cycle arrest. The multiple protein-protein interactions and modifications of p53, like phosphorylation and sumoylation, are additional denominators for the p53 action.

Overexpression of mPER2 results in reduced cellular proliferation and rapid apoptosis in tumor cells, but not in NIH3T3 cells and alters the expression of apoptosis-related genes, especial p53, and regulates the expression of proteins involved directly or indirectly in apoptosis (Hui et al., 2006).

So, we suspect that $m P e r 2$ may influence cells damaged by UVC. In the present study, we applied mPER2-upregulated $\mathrm{NIH} 3 \mathrm{~T} 3$ cells to reveal the relationship of $m P e r 2$ and the cells damaged by UVC.

\section{MATERIALS AND METHODS}

\section{Plasmid}

The eukaryotic expression vector pcDNA3.1(+)-mPer2 containing a cDNA copy of $m$ Per2 (GenBank number NM-011066) was used in this study. The mPer2 was confirmed as being in frame with no mutations by DNA sequencing.

\section{Antibodies}

Mouse antibodies against mPER2, p53 and Actin were purchased from Sigma (Sigma, St Louis, MO). Rabbit antigoat IgG and horseradish peroxidase-conjugated secondary antibodies were purchased from Santa Cruz Biotechnology (Santa Cruz, CA).

\section{Phorbol 12-myristate 13-acetate (PMA) inducing period genes}

NIH3T3 cells were maintained with Dulbecco's modiced Eagle medium (DMEM) from Invitrogen Corporation (Carlsbad, CA) containing $10 \%$ fetal calf serum, $100 \mathrm{mg} / \mathrm{ml}$ penicillin and $100 \mathrm{U} / \mathrm{ml}$ streptomycin. Before all experiments, cells were re-suspended in serum-free DMEM medium, seeded to the plates. To induce circadian genes, cells were treated with PMA $(0.5 \mu \mathrm{mol})$.

\section{Transfection}

NIH3T3 cells were maintained in Dulbecco's modified Eagle's medium (Hyclone, Logan, UT) supplemented with antibiotics and $10 \%$ fetal calf serum (Hyclone, Logan, UT) in an atmosphere of humidified $95 \%$ air and $5 \% \mathrm{CO}_{2}$ at $37^{\circ} \mathrm{C}$. The cells were transfected with the plasmids indicated using Lipofectamine transfection reagent (Invitrogen Corporation, Carlsbad, CA). Cell lysates were prepared $48 \mathrm{~h}$ later for the examination of protein expression.

\section{UV irradiation}

NIH3T3 cells were cultured under a humidified atmosphere of $5 \% \mathrm{CO}_{2}$ at $37^{\circ} \mathrm{C}$ in RPMI 1640 medium (Sigma, St. Louis, MO) supplemented with $10 \%$ fetal bovine serum. Cells were exposed to UVC $\left(30 \mathrm{~J} / \mathrm{m}^{2}\right)$ with UVC 500 Ultraviolet Crosslinker (Amersham Pharmacia Biotech, Piscataway, NJ) (Ma- sato et al., 2007). During irradiation, cells were incubated in PBS and maintained on a $37^{\circ} \mathrm{C}$ water bath (Brenneisen et al., 1998). Following irradiation, PBS was replaced again by fresh medium.

\section{Cell growth and proliferation}

Cell growth and proliferation was assessed using the cell colony-forming assay, cell growth curves and the MTT assay according to the standard protocol (Mosmann, 1983). Each assay was repeated three times.

\section{Flow cytometry}

The cells were harvested, washed with phosphate-buffered saline and fixed in $70 \%$ ethanol for $30 \mathrm{~min}$ at $4^{\circ} \mathrm{C}$, then treated with $50 \mu \mathrm{g} / \mathrm{ml}$ of RNase A (Sigma, St. Louis, MO), stained with $50 \mu \mathrm{g} / \mathrm{ml}$ propidium iodide for $20 \mathrm{~min}$ at $4^{\circ} \mathrm{C}$ without light, and analyzed by flow cytometry for DNA synthesis and cell cycle status (Beckman Coulter Elite, Miami Lakes, FL, USA).

To analyze the expression of apoptosis-related proteins, the cells were harvested, fixed in $70 \%$ ethanol for 30 min at $4{ }^{\circ} \mathrm{C}$ and incubated with $0.1 \%$ saponin for $20 \mathrm{~min}$. They were then incubated with primary antibodies (Sigma, St. Louis, MO) at a dilution of 1:100 for $30 \mathrm{~min}$ and incubated with fluoresceinisothiocyanate-conjugated secondary antibodies (Chemicon, Temecula, CA) at a dilution of 1:100 for $30 \mathrm{~min}$. The cells were then analyzed by flow cytometry.

\section{Western blot analysis}

Cells were lysed with cold RIPA lysis buffer containing protease inhibitors (AppliChem Inc., St. Louis, MO), and proteins were collected by centrifugation. Protein concentrations were determined using the bicinchoninic acid (BCA) protein assay (Pierce, Rockford, IL) and transferred electro-phoretically to polyvinylidene difluoride (PVDF) membrane (Pierce). Detection was carried out using an enhanced chemiluminescence reagent (Pierce, Rockford, IL).

\section{Comet assay}

The alkaline version of the comet assay was carried out as described in a previous report (Lehmann et al., 1998). In short, $3.5 \mathrm{~h}$ after UV irradiation, cells were trypsinized, embedded in $1 \%$ Agarose on glass slides, and lysed for $1 \mathrm{~h}$ in alkaline TBS buffer including $1 \%$ Triton-X100 and $1 \% \mathrm{~N}$-laurylsarcosinate at $\mathrm{pH} 12-13$. After neutralization in $0.4 \mathrm{M}$ Tris, $\mathrm{pH} 7.5$, cells were stained with ethidium bromide and subjected to electrophoresis at $25 \mathrm{~V}$ for $1 \mathrm{~h}$. All steps were performed at $48^{\circ} \mathrm{C}$. DNA migration lengths were determined by computer-aided analysis (Comet software 3.0, Kinetic Imaging, Liverpool, UK). The mean value of 50 cells per treatment group was calculated.

\section{RT-PCR}

Total RNA was isolated with Trizol reagent (Invitrogen). RTPCR for mPer1 and mPer2 and GAPDH mRNA was carried out. Details of the primers and the GenBank accession numbers are given in Table 1.

\section{Statistical analysis}

Data were presented as the mean $\pm S D$, and the Student's $t$-test or one-way ANOVA was used for comparisons among different groups. $p$-values of less than 0.05 were considered statistically significant. 
Table 1. Gene nomenclature, GenBank accession code, primer sequences, and predicted sizes of the amplified products for the different genes studied

\begin{tabular}{llll}
\hline Gene & $\begin{array}{c}\text { Accession } \\
\text { number }\end{array}$ & Forward primer & $\begin{array}{c}\text { Size } \\
(\mathrm{bp})\end{array}$ \\
\hline Per1 & Gl:7416849 & CCCTGCTACCTTCCCTTCT & Rev1 \\
Per2 & NM_011066 & GCAACGAGCCCTCAGACA & GACGACTCAGTAACCT \\
P53 & AF161020 & ATGGAGGATTCACAGTCGGA & GGACCCACGGATGAACCTA \\
GAPDH & M88354 & TCACTGCCACCCAGAAGA & TCAGTCTGAGTCAGGCCCC \\
\hline
\end{tabular}

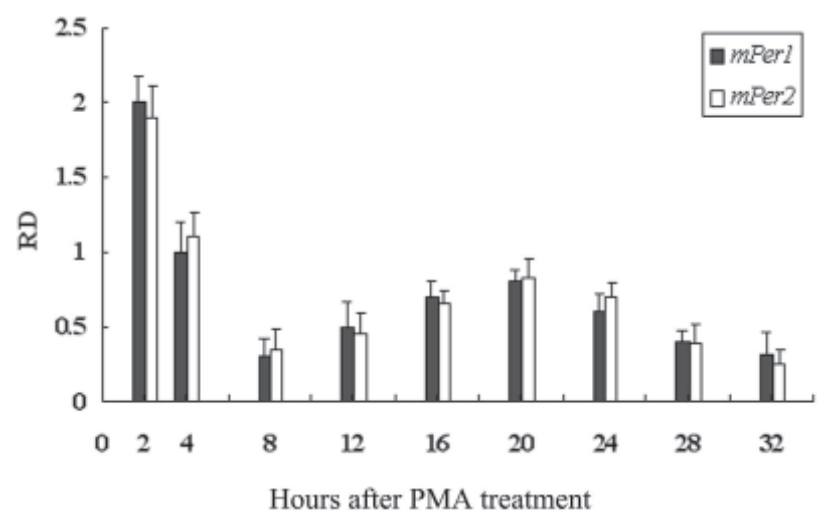

Fig. 1. PMA-induced circadian expression of $m P e r 1$ and $m P e r 2$ mRNA in NIH3T3. NIH3T3 cells were treated with PMA $(0.5 \mu \mathrm{mol})$ for $60 \mathrm{~min}$. Total RNA was isolated from cells and mRNA was analyzed by RT-PCR controlled by GAPDH at $0 \mathrm{~h}, 2 \mathrm{~h}, 4 \mathrm{~h}, 8 \mathrm{~h}, 12$, $16 \mathrm{~h}, 20 \mathrm{~h}, 24 \mathrm{~h}, 28 \mathrm{~h}$ and $32 \mathrm{~h}$ after PMA treatment. The test was repeated 4 times.

\section{RESULTS}

\section{The express of $m$ Per1 and $m$ Per2 in different group of NIH3T3 cells}

Parental NIH3T3 cells normally produce very low and barely detectable levels of $m P e r 1$ and mPer2. Stimulation of the NIH3T3 cells with PMA strongly induced mPer1 and mPer2 mRNA expression. The level of PMA-induced mPer1 and mPer2 mRNA reached a peak within 1-4 $\mathrm{h}$ and declined to basal levels at $8 \mathrm{~h}$ after inducing with PMA, and then the expression of $m P e r 1$ and $m P e r 2$ demonstrated circadian pattern (Fig. 1), whose nadirs and peaks were at $8 \mathrm{~h}$ and $20 \mathrm{~h}$ after inducing with PMA, respectively.

We established mPER2-overexpressing cells by transfecting mPER2 cDNA in a sense orientation into NIH3T3 cells. The cells transfected with empty vector served as controls. Successful transfer of the mPer2 gene using Lipofectamine 2000 was confirmed by RT-PCR and western blotting (Fig. 2).

\section{Cell growth and proliferation}

NIH3T3 cells were irradiated by UVC at $12 \mathrm{~h}$ or $24 \mathrm{~h}$ after inducing with PMA, $4 \mathrm{~h}$ after the nadir and the peak of the expression of the circadian genes (mPer1 and mPer2), which were almost the nadir and the peak of the expression of their proteins. The colony formation assays, cell growth curves and the MTT assay were carried out to evaluate the effect of UVC on NIH3T3 cell growth and proliferation.

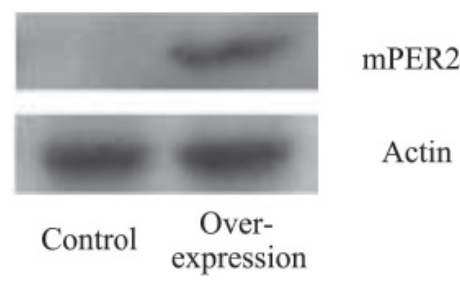

Fig. 2. Detection of $m P e r 2$ expression by western blot. The pcDNA3.1(+)-mPer2 transfected NIH3T3 cells (Overexpression) obviously expressed mPER2 protein.

PMA induced the circadian expression of mPer1 and mPer2 accompanied the different effect of UVC on the growth and proliferation of $\mathrm{NIH} 3 \mathrm{~T} 3$ cell at different time after inducing with PMA. Fig. 3 demonstrated the growth and proliferation of NIH3T3 cells treated with UVC at $12 \mathrm{~h}$ (PMA-12) or 24 h (PMA-12) after PMA treatment and without PMA treatment (Non-PMA). One-way ANOVA displayed significant difference of the colony-forming efficiency of NIH3T3 cells in non-PMA treatment (Non-PMA), $12 \mathrm{~h}$ after PMA treatment (PMA-12 h) and $24 \mathrm{~h}$ after PMA treatment (PMA-24 h), and revealed significant difference in PMA-24 $\mathrm{h}$ to PMA-12 $\mathrm{h}$ and PMA-24 $\mathrm{h}$ to Non-PMA, and non-significant difference in PMA-12h to NonPMA (Fig. 3A). Cell growth curves and MTT assay indicated revealed the same pattern of cell growth and proliferation in NIH3T3 cells induced by PMA (Fig. 3B and Fig. 3C).

The colony-forming efficiency of mPER2 overexpressing cells irradiated with UVC was significantly higher than that in control cells (Fig. 4A). Cell growth curves and the MTT assay indicated a significant difference in cell growth speed between the two groups (Fig. 4B and 4C).

\section{Cell death and apoptosis}

Different NIH3T3 cells were irradiated at $12 \mathrm{~h}$ and $24 \mathrm{~h}$ after inducing with PMA, respectively. Cell apoptosis was determined by flow cytometry. The result displayed significant difference of the apoptotic peaks of NIH3T3 cells in $12 \mathrm{~h}$ after PMA treatment (PMA-12 h) and $24 \mathrm{~h}$ after PMA treatment (PMA-24 h) (Fig. 5). The NIH3T3 cells overexpressing mPER2 had much higher apoptotic peaks than the vector control cells (Fig. 6).

\section{DNA damage}

DNA-damaging effects of UV-B were analyzed using the alkaline comet assay which, under the applied experimental conditions, indicates the level of nucleotide excision repair of UV-B-induced DNA lesions.

Short tails of migrating DNA are visible in NIH3T3 cells at 

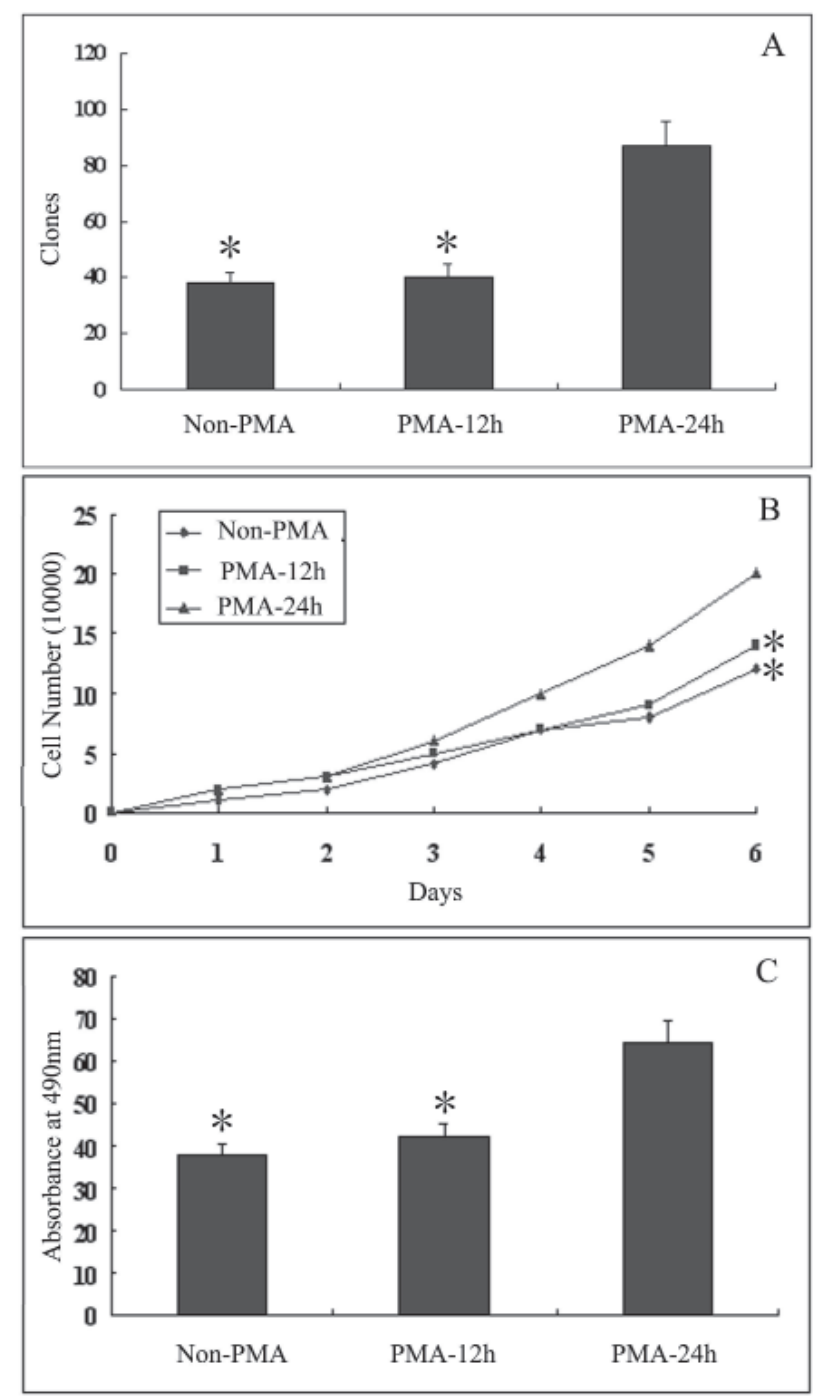

Fig. 3. The influence of PMA on cell growth and proliferation in NIH3T3 cells irradiated by UVC. The growth and proliferation of $\mathrm{NIH} 3 \mathrm{~T} 3$ cells were treated with UVC at $12 \mathrm{~h}(\mathrm{PMA}-12)$ or $24 \mathrm{~h}$ (PMA-12) after PMA treatment and without PMA treatment (NonPMA). Non-PMA, PMA-12 and PMA-24 indicate NIH3T3 cells untreated with PMA, NIH3T3 cells $12 \mathrm{~h}$ after PMA treated with PMA and $\mathrm{NIH} 3 \mathrm{~T} 3$ cells $24 \mathrm{~h}$ after PMA treated with PMA. (A) The colony formation assays. One-way ANOVA reveals significant difference $(F(2,6)=39.32, p<0.001)$ in the three groups. The colony-forming efficiency of PMA-24 is significantly higher than that of PMA-12 $(p<0.001)$ and Non-PMA $(p<0.001)$. (B) Cell growth curves. The numbers under the horizontal axis indicate the days for cell culture. The results at 6 days indicate a significant difference in cell growth speed among the three groups (One-way ANOVA, $F(2,6)=20.89$, $p=0.002$ ), and the cell growth speed in PMA-24 was higher than that of the other two groups (PMA-24 to Non-PMA, $p=0.001$; PMA24 to PMA-12, $p=0.004)$. (C) The MTT assay. Absorbance at 490 $\mathrm{nm}$ showed a significant difference in the three groups (One-way ANOVA, $F(2,6)=12.59, p=0.007)$ and PMA-24 was different from Non-PMA $(P=0.004)$ and PMA-12 $(p=0.007) .{ }^{*} p<0.05$.

$24 \mathrm{~h}$ after PMA treatment (PMA-24 h) (Fig. 7A) and mPER2overexpression NIH3T3 cells (Fig. 7B, 8), which demonstrated that mPer2 play an protective role in NIH3T3 cells damaged by UVC.
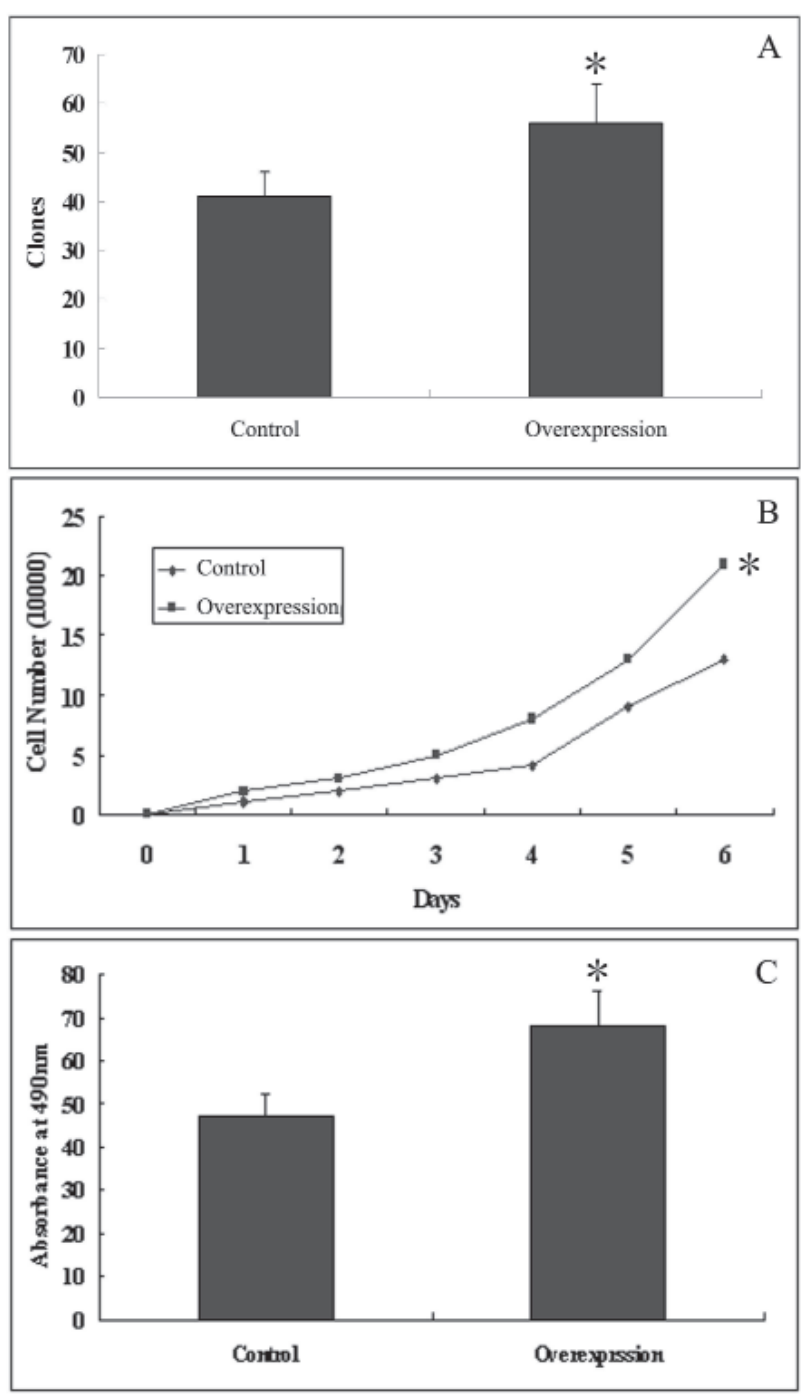

Fig. 4. The protective effect of mPER2 overexpression on NIH3T3 cells damaged by UVC. (A) The colony formation assays. mPER2 increased colony formation dramatically. The colony-forming efficiency of mPER2 overexpression NIH3T3 cells (Overexpression) was significantly higher than that of Control group (Student's $t$-test, $t=4.419, p=0.012$ ). (B) Cell growth curves. The results indicate that the cell growth speed in Overexpression was higher than that of Control group (Student's $t$-test, $t=4.143, p=0.014$ ). (C) The MTT assay. Absorbance at $490 \mathrm{~nm}$ showed a significant increase in Overexpression compared with the other groups (Student's $t$-test, $t$ $=5.169, p=0.007) .{ }^{*} p<0.05$.

\section{The expression of $\mathrm{p} 53$}

The housekeeping gene GAPDH was used to ensure the integrity of the RNA and equality of loading. RT-PCR analysis showed that the expression of p53 was upregulated in mPER2-overexpressing NIH3T3 cells compared with vector control cells. After protein normalization to Actin levels, western blot analysis also demonstrated the same pattern of the level of p53 in different group (Fig. 9). 

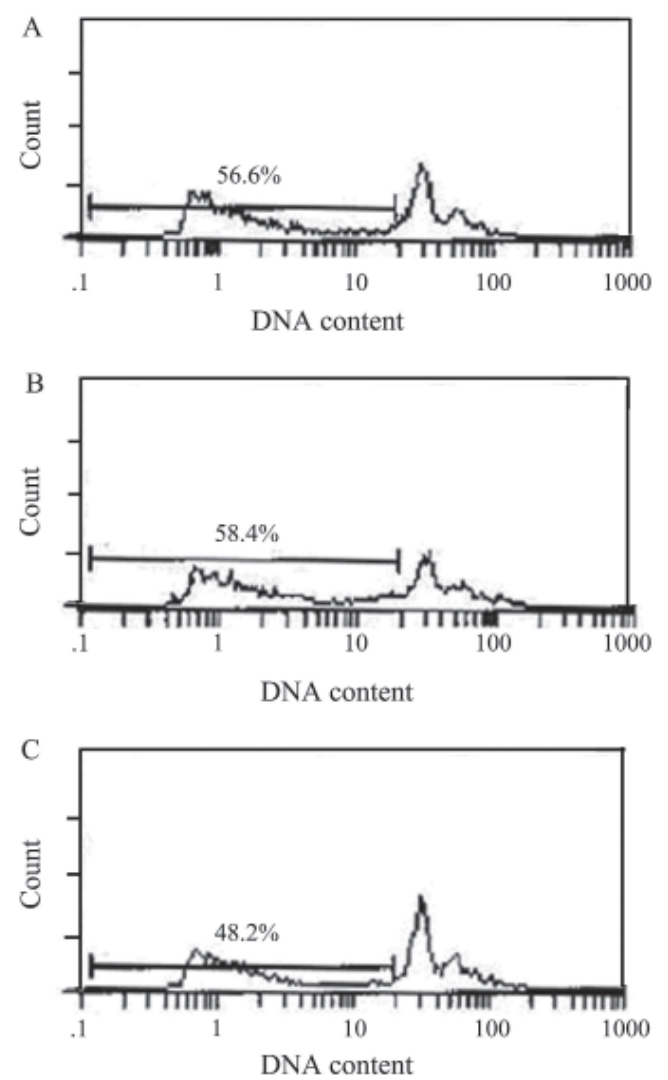

Fig. 5. Flow cytometric analysis of apoptosis in NIH3T3 cells irradiated with UVC treated with PMA. Horizontal and vertical axes represent DNA content and cell number, respectively. (A) NonPMA, (B) PMA-12 h, (C) PMA-24 h. The percentage of sub-G1 cells undergoing apoptosis is indicated (bar). The NIH3T3 at $24 \mathrm{~h}$ after PMA treatment $(C)$ had a much lower apoptotic peak than the other two groups $(A, B)$.

\section{DISCUSSION}

The mechanism of circadian oscillation based on the molecular feedback loops consists of several circadian genes and their protein products. Up to now, many core circadian clock genes have been identified in mammals and humans (Dunlap, 1999; Morse and Sassone-Corsi, 2002), and the Per2 gene is regarded as an indispensable component of the circadian clock (Zheng et al., 2001). Gene targeting studies have demonstrated that the deletion of mPer2 induces arrhythmicity at both the behavioral and molecular levels (Bae et al., 2001). Mice without mPER2 function have a transient rhythm with a shortened period length of $22 \mathrm{~h}$. A majority of mutant mice lose the persistence of circadian rhythm when placed in freerunning conditions (Lee, 2005).

Several studies have reported that circadian genes are expressed in both SCN and peripheral tissue. Using peripheral cells and cell lines, several stimuli such as high concentrations of serum, forskolin, or phorbol 12-myristate 13-acetate (PMA) were reported to induce period genes. In the present study, PMA was used to stimulated NIH3T3 cells. The results demonstrated that the expression of circadian genes, including mPer1 and mPer2, in NIH3T3 cell treated with PMA revealed
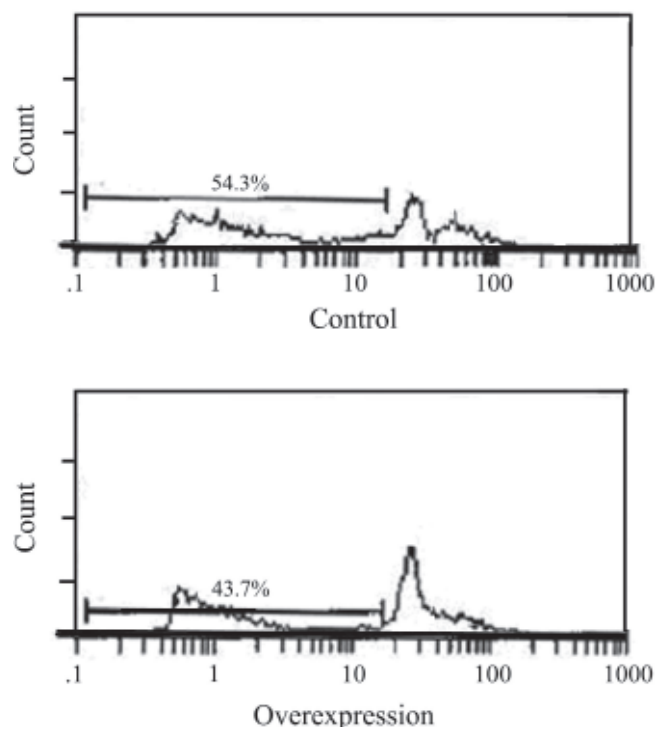

Fig. 6. Flow cytometric analysis of apoptosis in mPER2-overexpression NIH3T3 cells irradiated with UVC. The mPER2-overexpression NIH3T3 had a much lower apoptotic peak than the vector control cells.
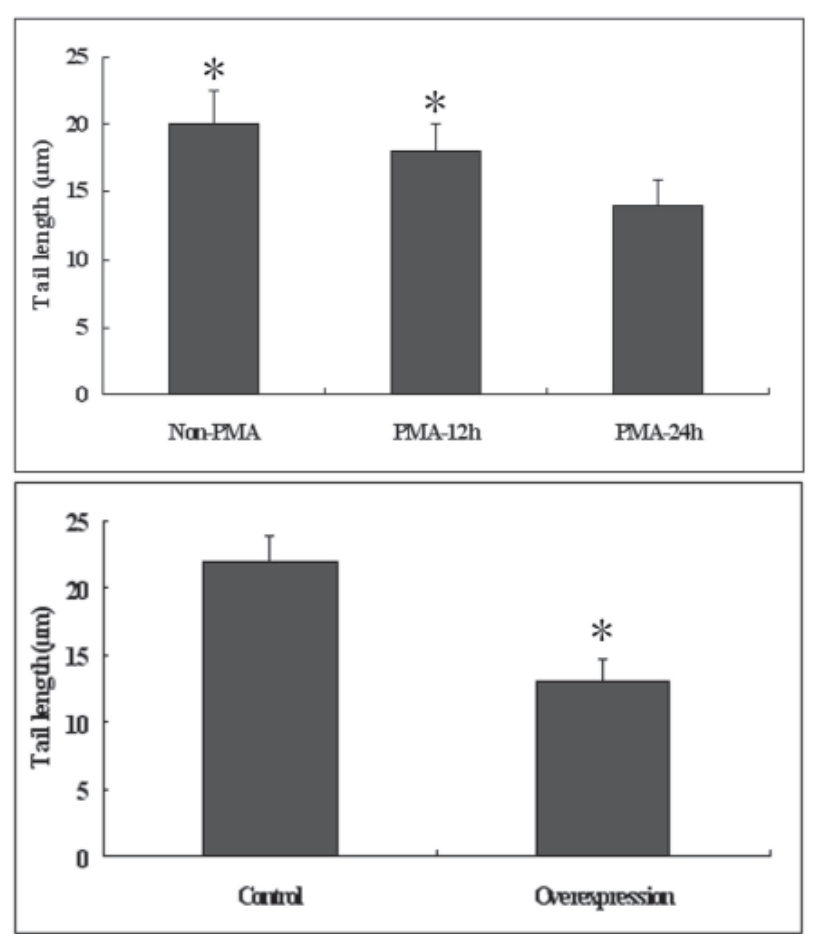

Fig. 7. Comet assay of UVC-irradiated cells. (A) NIH3T3 cells treated with PMA. One-way ANOVA revealed significant difference $(F(2,6)=13.77, p=0.006)$. PMA-24 h was significant to PMA-12 h $(p=0.002)$ and Non-PMA $(p=0.022)$, but others were non-significant difference. (B) mPER2-overexpression NIH3T3 cells. Student's $t$-Tests demonstrated the tails of migrating DNA in Overexpression was shorter than that of Control $(t=3.567, p=0.023)$. ${ }^{*} p<0.05$. 


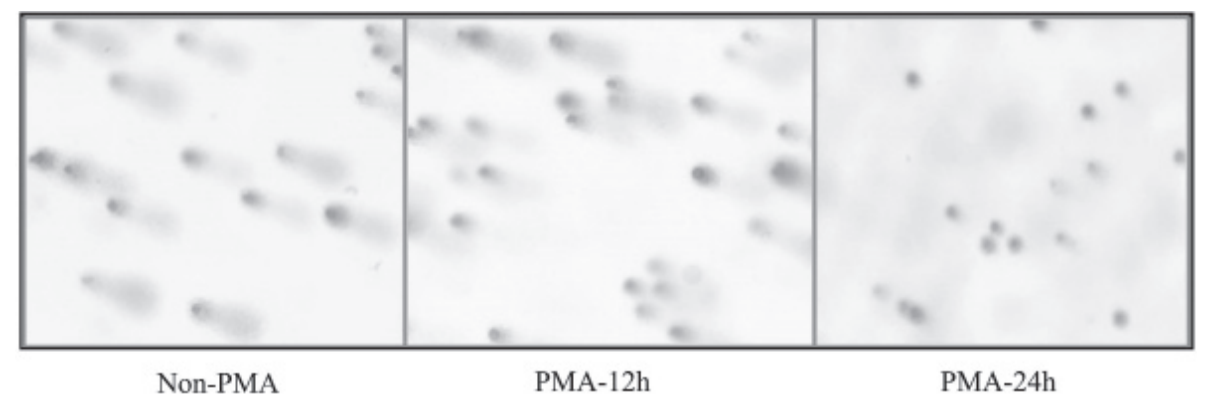

Fig. 8. Typical nuclear profiles of lens epithelial cells in the comet slides. The nuclei of normal cells are round, and that of damaged cells show a tail.

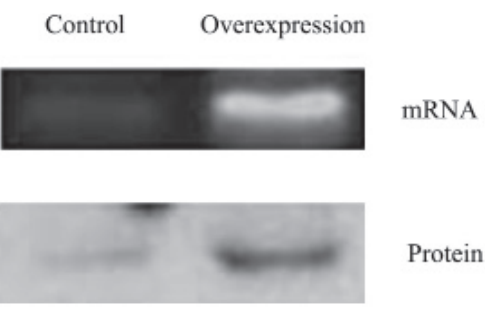

Fig. 9. Analysis of $\mathrm{P} 53$ in NIH3T3. Upper: Reverse transcriptionpolymerase chain reaction (RT-PCR) analysis of $p 53$. Lower: Western blot analysis of $p 53$. RT-PCR and western blot analysis demonstrated increased amounts of p53 in mPER2-overexpressing cells than in vector control cells.

circadian pattern, similar to the former report (Kentaro et al., 2002), whose nadirs and peaks were at $12 \mathrm{~h}$ and $24 \mathrm{~h}$ after PMA treatment, respectively.

UV radiation from sunlight exposure induces DNA damage that is potentially lethal to cells and is carcinogenic to animals. Studies in fission and budding yeasts have demonstrated that genes that promote survival in UV light encode both DNA repair factors and checkpoint proteins that regulate the cell cycle in response to DNA damage. These genes are conserved among eukaryotes, so diverse model systems may be used to address questions of molecular mechanism. The pyrimidine dimer is the most abundant form of DNA damage known to be induced by UV (Cadet et al., 2005).

It is now documented that alterations in circadian rhythm can be associated with cancers in both animal and human tumors (Filipski et al., 2002; Chen et al., 2005). The mice deficient in the mPer2 gene were cancer-prone. After radiation, these mice showed a marked increase in tumor development and reduced apoptosis in thymocytes (Fu et al., 2002). Overexpression of mPER2 in the mouse Lewis lung carcinoma cell line (LLC) and mammary carcinoma cell line (EMT6) results in reduced cellular proliferation and rapid apoptosis, but not in NIH3T3 cells (Hui et al., 2006). In the present study, the results demonstrated that $m P e r 2$ exhibited a significant protective effect on NIH3T3 cells damaged by UVC, as evaluated by MTT assay, cell growth curves and cell colony-forming assay, which suggest that MPER2 may attenuate DNA damage in cells induced by UVC.

Overexpressed mPER2 also altered the expression of apoptosis-related genes. The mRNA and protein levels of $\mathrm{c}-\mathrm{Myc}, \mathrm{Bcl}-\mathrm{XL}$ and $\mathrm{Bcl}-2$ were downregulated, whereas the expression of p53 and bax was upregulated in mPER2-overexpressing cells compared with control cells transferred with empty plasmid (Hui et al., 2006), which was consistent with the present result that the p53 was upregulated in mPER2overexpressing NIH3T3 cells.

p53, a central factor in cellular stress responses, governs the protective and adaptive responses following several types of damage, such as DNA damage, hypoxia, nucleotide imbalance, and oxidative stress (Levine, 1997). p53, determining the fate of the cell based on the severity of the damage, can halt cell cycle progression and direct damage repair. In case of extensive and unrepairable damage, p53 induces apoptosis. p53 regulates genes contributing to the cell cycle, DNA repair, and apoptosis. p53 was found to be stabilized by UV radiation already in 1984 (Maltzman and Czyzyk, 1984). Since then, it has become apparent that $\mathrm{p} 53$ plays a central role in the cellular responses provoked by UV radiation, amongst other stress inducers (Prives and Hall, 1999; Vousden and Lu, 2002). p53 is essential for the protective UV responses in skin, and loss of its function promotes UV-induced skin tumorigenesis (Ziegler et al., 1994; de Gruijl et al., 2001). Consistent with Hui Hua's study (Hui et al, 2006), the expression of p53 was upregulated in mPER-overexpression NIH3T3 cells. So, the protective effect of MPER2 on cell damaged by UVC may be result from the upregulated $\mathrm{p} 53$.

In summary, NIH3T3 cells at the peak of the expression of $m$ Per2 induced by PMA demonstrated little damage with UVC evaluated by MTT assay, cell growth curves and cell colonyforming assay, compared with that at the nadir of the expression of mPer2. Overexpression of mPER2, accompanied p53 upregulated, also demonstrated protective effect on NIH3T3 cells damaged by UVC. These results suggest that $m P e r 2$ plays a protective effect on cells damaged by UVC, whose mechanism may be involved in upregulated p53.

\section{ACKNOWLEDGMENTS}

This research was supported by National Basic Research Program of China (973 Program), No. 2011CB711000, The Opening Foundation of the State Key Laboratory of Space Medicine Fundamentals and Application, Chinese Astronaut Research and Training Center, Grant NO. SMFA09K04 and CMB, No. 88-486 to Z. Wang.

\section{REFERENCES}

Abarca, C., Albrecht, U. and Spanagel, R. (2002) Cocaine sensitization and reward are under the influence of circadian genes and rhythm. Proc. Natl. Acad. Sci. USA 99, 9026-9030. 
Andretic, R., Chaney, S. and Hirsh, J. (1999) Requirement of circadian gene for cocaine ensitization in Drosophila. Science 285, 10661068

Bae, K., Jin, X., Maywood, E. S., Hastings, M. H., Reppert, S. M. and Weaver, D. R. (2001) Differential functions of mPer1, mPer2, and mPer3 in the SCN circadian clock. Neuron 30, 525-536.

Brenneisen, P., Blaudschun, R., Bernards, M., Wenk, J., Wlaschek, M., Meyer-Ingold, W., Schauen, M., Krieg, T. and Scharffetter-Kochanek, K. (1998) Increased temperature: a potentially important side-effect of ultraviolet radiation treatment leading to induction of interstitial collagenase/matrix metalloproteinase-1. Br. J. Dermatol. 139, 537-539.

Cadet, J., Sage, E. and Douki, T. (2005) Ultraviolet radiation-mediated damage to cellular DNA. Mutat. Res. 571, 3-17

Chen, S. T., Choo, K. B., Hou, M. F., Yeh, K. T., Kuo, S. J. and Chang, J. G. (2005) Deregulated expression of the PER1, PER2 and PER3 genes in breast cancers. Carcinogenesis. 26, 1241-1246.

Czeisler, C. A., Duffy, J. F., Shanahan, T. L., Brown, E. N., Mitchell, J. F., Rimmer, D. W., Ronda, J. M., Silva, E. J., Allan, J. S., Emens, J. S., Dijk, D. J. and Kronauer, R. E. (1999) Stability, precision, and near-24-hour period of the human circadian pacemaker. Science 284, 2177-2181.

Dazard, J. E., Gal, H., Amariglio, N., Rechavi, G., Domany, E. and Givol, D. (2003) Genome-wide comparison of human keratinocyte and squamous cell carcinoma responses to UVB irradiation: implications for skin and epithelial cancer. Oncogene 22, 2993-3006.

de Gruijl, F. R., van Kranen, H. J. and Mullenders, L. H. (2001). UVinduced DNA damage, repair, mutations and oncogenic pathways in skin cancer. J. Photochem. Photobiol. 63, 19-27.

Delaunay, F. and Laudet, V. (2002) Circadian clock and microarrays: mammalian genome gets rhythm. Trends Genet. 18, 595-597.

Dunlap, J. C. (1999) Molecular bases for circadian clocks. Cell 96, 271-290.

Ebisawa, T., Uchiyama, M., Kajimura, N., Mishima, K., Kamei, Y., Katoh, M., Watanabe, T., Sekimoto, M., Shibui, K., Kim, K., Kudo, Y., Ozeki, Y., Sugishita, M., Toyoshima, R., Inoue, Y., Yamada, N., Nagase, T., Ozaki, N., Ohara, O., Ishida, N., Okawa, M., Takahashi, K. and Yamauchi, T. (2001) Association of structural polymorphisms in the human period3 gene with delayed sleep phase syndrome. EMBO Rep. 2, 342-346.

Fei, P. and El-Deiry, W. S. (2003) p53 and radiation responses. Oncogene. 22, 5774-5783

Filipski, E., King, V.M., Li, X., Granda, T.G., Mormont, M.C., Liu, X., Claustrat, B., Hastings, M.H. and Lévi, F. (2002) Host circadian clock as a control point in tumor progression. J. Natl. Cancer Inst. 94, 690-697.

Fu, L., Pelicano, H., Liu, J., Huang, P. and Lee, C. (2002) The circadian gene Period2 plays an important role in tumor suppression and DNA damage response in vivo. Cell 111, 41-50.

Gentile, M., Latonen, L. and Laiho, M. (2003) Cell cycle arrest and apoptosis provoked by UV radiation-induced DNA damage are transcriptionally highly divergent responses. Nucleic. Acids Res. 31, 4779-4790.

Haus, E. (2002) Chronobiology of the Mammalian Response to Ionizing Radiation: Potential Applications in Oncology. Chronobio. Int. 19, 77-100

He, Y. Y., Huang, J. L., Sik, R. H., Liu, J., Waalkes, M. P. and Chignell, C. F. (2004) Expression profiling of human keratinocyte response to ultraviolet A: implications in apoptosis. Invest. Dermatol. 122, 533-543.

Hui, H., Yueqi, W., Chaomin, W., Yanyou, L., Bin, Z., Chunlei, Y., Xiaojia, W., Zhengrong, W., Cornelissen-Guillaume, G. and Halberg, F. (2006) Circadian gene mPer2 overexpression induces cancer cell apoptosis. Cancer Sci. 97, 589-596.

Kentaro, O., Yoshihisa, N. and Masaki, T. (2002) Intracellular calcium mobilization induces period genes via MAP kinase pathways in NIH3T3 cells. FEBS Letters 516, 101-105.

Lee, C. C. (2005) The circadian clock and tumor suppression by mammalian period genes. Meth Enzymol. 393, 852-861.

Leena, L. and Marikki, L. (2005) Cellular UV damage responses-Func- tions of tumor suppressor p53. Biochimica. et. Biophysica. Acta. 1755, 71-89.

Lehmann, J., Pollet, D., Peker, S., Steinkraus, V. and Hoppe, U. (1998) Kinetics of DNA strand breaks and protection by antioxidants in UVA- or UVBirradiated HaCaT keratinocytes using the single cell gel electrophoresis assay. Mutat. Res. 40, 797-108.

Levine, A. J. (1997) p53, the cellular gatekeeper for growth and division. Cell 88, 323-331.

Liu, Y., Wang, Y., Wan, C., Zhou, W., Peng, T., Liu, Y., Wang, Z., Li, G., Cornelisson, G. and Halberg, F. (2005) The role of mper1 in morphine dependence in mice. Neuroscience 130, 383-388.

Maltzman, W. and Czyzyk, L. (1984) UV irradiation stimulates levels of p53 cellular tumor antigen in nontransformed mouse cells. Mol. Cell Biol. 4, 1689-1694.

Masato, I., Isamu, O., Kenji, T., Taroh, S., Kimio, Y., Masahiro, F. and Kazuhiko, N. (2007) Down-regulation of survivin by ultraviolet C radiation is dependent on p53 and results in G2-M arrest in A549 cells. Cancer Letters 248, 292-298.

McKay, B. C., Stubbert, L. J., Fowler, C. C., Smith, J. M., Cardamore, R. A. and Spronck, J. C. (2004) Regulation of ultraviolet light-induced gene expression by gene size. Proc. Natl. Acad. Sci. USA $101,6582-6586$

Meek, D. W. (2004) The p53 response to DNA damage. DNA Repair (Amst) 3, 1049-1056.

Morse, D. and Sassone-Corsi, P. (2002) Time after time: inputs to and outputs from the mammalian circadian oscillators. Trends Neurosci. 25, 632-7.

Mosmann, T. (1983) Rapid colorimetric assay for cellular growth and survival: application to proliferation and cytotoxicity assays. J. Immunol. Methods 65, 55-63.

Panda, S., Antoch, M. P., Miller, B. H., Su, A. I., Schook, A. B., Straume, M., Schultz, P. G., Kay, S. A., Takahashi, J. S. and Hogenesch, J. B. (2002) Coordinated transcription of key pathways in the mouse by the circadian clock. Cell 109, 307-320.

Prives, C. and Hall, P. A. (1999) The p53 pathway. J. Pathol. 187, 112126.

Ravanat, J. L., Douki, T. and Cadet, J. (2001) Direct and indirect effects of UV radiation on DNA and its components. J. Photochem. Photobiol. B63, 88-102.

Reppert, S. M. and Weaver, D. R. (2002) Coordination of circadian timing in mammals. Nature 418, 935-941.

Sesto, A., Navarro, M., Burslem, F. and Jorcano, J. L. (2002) Analysis of the ultraviolet $B$ response in primary human keratinocytes using oligonucleotide microarrays. Proc. Natl. Acad. Sci. USA 99, 29652970.

Storch, K. F., Lipan, O., Leykin, I., Viswanathan, N., Davis, F. C., Wong, W. H. and Weitz, C. J. (2002) Extensive and divergent circadian gene expression in liver and heart. Nature 417, 78-83.

Takao, J., Ariizumi, K., Dougherty, I. I. and Cruz Jr, P. D. (2002) Genomic scale analysis of the human keratinocyte response to broadband ultraviolet-B irradiation. Photodermatol. Photoimmunol. Photomed. 18, 5-13.

Tornaletti, S. and Hanawalt, P. C. (1999) Effect of DNA lesions on transcription elongation. Biochimie. 81, 139-146.

Tyrrell, R. M (1994). The molecular and cellular pathology of solar ultraviolet radiation. Mol. Aspects Med. 15, 1-77.

Valery, C., Grob, J. J. and Verrando, P. (2001) Identification by cDNA microarray technology of genes modulated by artificial ultraviolet radiation in normal human melanocytes: relation to melanocarcinogenesis. J. Invest. Dermatol. 117, 1471-1482.

Vousden, K.H. and Lu, X. (2002) Live or let die: the cell's response to p53. Nat. Rev. Cancer 2, 594-604.

Zheng, B., Albrecht, U., Kaasik, K., Sage, M., Lu, W., Vaishnav, S., Li, Q., Sun, Z. S., Eichele, G., Bradley, A. and Lee, C. C. (2001) Nonredundant roles of the $\mathrm{mPer} 1$ and $\mathrm{mPer} 2$ genes in the mammalian circadian clock. Cell 105, 683-694.

Ziegler, A., Jonason, A. S., Leffell, D. J., Simon, J. A., Sharma, H. W. Kimmelman, J., Remington, L., Jacks, T. and Brash, D. E. (1994) Sunburn and p53 in the onset of skin cancer. Nature $372,773-776$. 